\title{
Author Correction: A systematic review of biomarkers to detect active tuberculosis
}

Emily MacLean, Tobias Broger (D), Seda Yerlikaya, B. Leticia Fernandez-Carballo, Madhukar Pai and Claudia M. Denkinger (iD)

Correction to: Nature Microbiology https://doi.org/10.1038/s41564-019-0380-2, published online 25 February 2019.

In the original version of this Analysis, author Seda Yerlikaya was mistakenly spelled as Seda Yerliyaka. This has now been amended.

Published online: 11 April 2019

https://doi.org/10.1038/s41564-019-0452-3 